\title{
Comparison of vibrotactile threshold and suprathreshold responses in men and women
}

\author{
RONALD T. VERRILLO \\ Institute for Sensory Research, Syracuse University, Syracuse, New York 13210
}

\begin{abstract}
Vibrotactile thresholds were measured on the thenar eminence of 12 men and 12 women at 10 sinusoidal frequencies. No significant differences between the two groups were observed. Magnitude estimation and production procedures carried out with 6 men and 6 women from the same groups showed that women perceive suprathreshold vibration stimuli as more intense than do men, although women and men do not differ in their estimation of the length of lines.
\end{abstract}

Differences in threshold sensitivity for men and women have been reported for several sense modalities. Auditory acuity, for instance, is about the same up to approximately age 50. During this period both sexes show a slight and gradual loss. Following age 50 men show an accelerated loss relative to women for frequencies of $3,000 \mathrm{~Hz}$ and above (Spoor, 1967). Corso (1963) states that the onset of presbycusis is more gradual and uniform for women, but that once started it is more rapid for women.

Procacci, Zoppi, Maresca, and Romano (1974) report that women are more sensitive to pain than men throughout the age span. They showed also that pain thresholds in women are closely related to the menstrual cycle. Others report little if any differences in pain thresholds (Clark \& Mehl, 1971). Sensitivity to odors has been shown to be more acute in women (Koelega, 1970; Köster, 1965; Schneider, 1967) and also to be related to the menstrual cycle (Köster, 1965; Le Magnen, 1953). The author was unable to find comparative studies between men and women regarding visual acuity.

Women were found to be more sensitive to vibration than men by Goff, Rosner, Detre, and Kennard (1965), who also report a gradual loss of sensitivity for women with age beginning in the late teens. Men, on the other hand, were found to have stable thresholds to $\mathbf{4 5}$ years of age before sensitivity decreases. A number of studies, however, found no differences between men and women with respect to vibrotactile threshold measurements (Plumb \& Meigs, 1961; Steinberg \& Graber, 1963; Verrillo \& Ecker, 1977).

All of the studies relating to sensory functions and sex report threshold data. None have dealt with suprathreshold phenomena. The present investigation was undertaken to determine if differences exist be-

This research was supported by Grant NS-09940 from the National Institutes of Health, U.S. Department of Health, Education, and Welfare. tween men and women in their sensitivity to vibration and in their perceived magnitudes of suprathreshold stimuli.

\section{APPARATUS AND METHOD}

The subjects were seated with forearm and hand, palm down, resting on a rigid surface. The vibrator was located on an adjustable platform beneath the rigid surface with the $2.9-\mathrm{cm}^{2}$ contactor protruding through a hole in the surface. The gap between the contactor and the edge of the rigid surround was $1.0 \mathrm{~mm}$. Before testing, the height of the vibrator was carefully adjusted so that the contactor pressed $1.0 \mathrm{~mm}$ into the skin of the thenar eminence. During testing, the sound of the vibrator was masked by narrowband noise centered at the test frequency and delivered through earphones.

Vibrotactile detection thresholds were determined for 12 men and 12 women using a Békésy automatic recording attenuator. Measurements were made at sinusoidal frequencies of 25,40 , $64,100,150,200,250,350,500$, and $700 \mathrm{~Hz}$. The stimuli were $1.0 \mathrm{sec}$ in duration, with a 1.0-sec interstimulus interval and a 100 -msec rise/fall time. The range of ages for the men was 19 to 30 years, with a mean age of 23 years. The range of ages for the women was 18 to 35 years, with a mean age of 24 years. The threshold results are mean values expressed in decibels referred to $1.0 \mu \mathrm{m}$ of peak displacement.

Suprathreshold responses were determined by direct scaling of subjective magnitude using the methods of magnitude estimation and magnitude production. The site of stimulation again was the thenar eminence of the right hands of six men and six women. Both groups had a mean age of 25 years, with a range of 20 to 30 years for the men and 20 to 37 for the women. Following determination of threshold at $250 \mathrm{~Hz}$, the subject was presented in random order 10 stimulus intensities ranging from 2 to $50 \mathrm{~dB}$ SL. The subject was requested to give a numerical estimate of the subjective intensity of the stimulus. No standard or modulus was used. Random intensity sequences were presented three times, and the mean of the second and third runs were averaged.

Following magnitude estimation, the subjects performed a magnitude-production procedure. Numbers were presented to the subject, who was asked to adjust the intensity of vibration, using a 120-dB continuous attenuator, so that its subjective magnitude matched that of the number. The methods used for magnitude estimation and production are described in greater detail in Verrillo, Fraioli, and Smith (1969). The data from the two procedures were plotted and, according to the procedure recommended by Hellman and Zwislocki (1963), the estimation and production data were combined to yield a curve of numerical magnitude balance. 


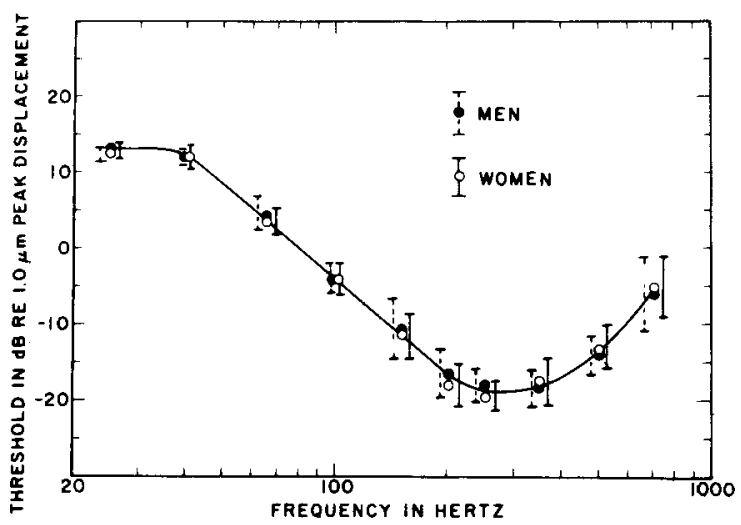

Figure 1. Absolute threshold of detectability (means) for sinusoidal vibrations for men $(\bullet)$ and women $(O)$ plotted as a function of frequency. The threshold of both groups is approximately the same. Standard deviations are represented by the vertical bars.

\section{RESULTS}

The comparison of male and female vibrotactile thresholds as a function of frequency is shown in Figure 1. It is obvious by inspection that there is no difference between the men and women tested in this experiment. Significance tests ( $t$ test) were performed at the three frequencies where the greatest differences were recorded $(200,250$, and $350 \mathrm{~Hz})$, but none of the mean differences between men and women were statistically significant. Measures of variability (standard deviation) in the two sets of data were close, as indicated by the horizontal bars in Figure 1. The threshold curves of both groups are composed of two segments, a low-frequency portion, which is relatively flat, and a high-frequency portion, which is U-shaped and has a maximum sensitivity in the region of $250 \mathrm{~Hz}$. This shape is typical of curves previously reported in the literature (Gescheider, 1976; Verrillo, 1963, 1968; Verrillo et al., 1969).

Figure 2 shows the results for men and women of the magnitude-estimation experiment. The mean measured thresholds at $250 \mathrm{~Hz}$ for the two groups were both $-18.3 \mathrm{~dB}$. The data show that at low levels of stimulation ( 2 and $6 \mathrm{~dB} \mathrm{SL}$ ), both men and women assign approximately the same numbers to represent the subjective magnitude of the stimulus. However, at levels of stimulation greater than $10 \mathrm{~dB}$ SL, women assign higher numbers than men to the same intensity level. The growth of sensation is more rapid for women at low intensity levels, but at higher levels the growth rate is the same for both men and women, with a slope of approximately .40 .

When asked to adjust the subjective intensity of the stimulus to numbers designated by the experimenter (magnitude production), the two groups produced the curves shown in Figure 3. The mean thresholds for the groups were very close: $-18.0 \mathrm{~dB}$ for the women and -18.2 for the men. The slope is slightly steeper for women for low numbers, resulting in a separation of the curves for high numbers. As the designated numbers were increased, men tended to adjust the stimulus to higher intensities than did the women.

The result of combining the two sets of data from Figures 2 and 3 by bisecting the differences between the magnitude estimation and magnitude production curves is shown in Figure 4. The combined thresholds for the estimation and production procedures was the same, $-18.2 \mathrm{~dB}$ for the two groups. The resulting magnitude balance curves again show a more rapid growth of sensation for women at low intensity levels and the same rate of growth at higher levels. The slope of the curves is approximately .45 at intensity levels above about $25 \mathrm{~dB}$ SL for both men and women. Women, however, appear to perceive the same intensity level as subjectively greater than do the men in this sample.

\section{DISCUSSION}

The results in Figure 1 indicate that men and women in their mid-20s do not differ with respect to

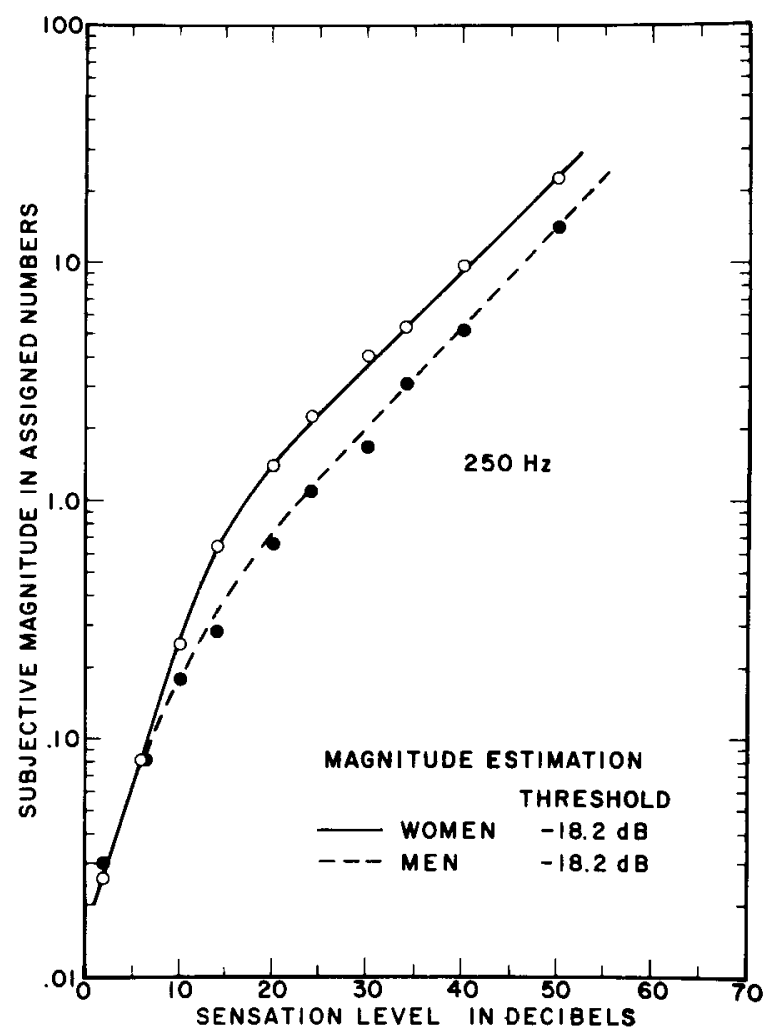

Figure 2. Absolute magnitude estimates (geometric means) of vibrotactile sensation as a function of sensation level for women $(O)$ and men $(\bullet)$. Vibration frequency was $250 \mathrm{~Hz}$. Above approximately $10 \mathrm{~dB}$ SL, the same intensity level is perceived as greater by women. 


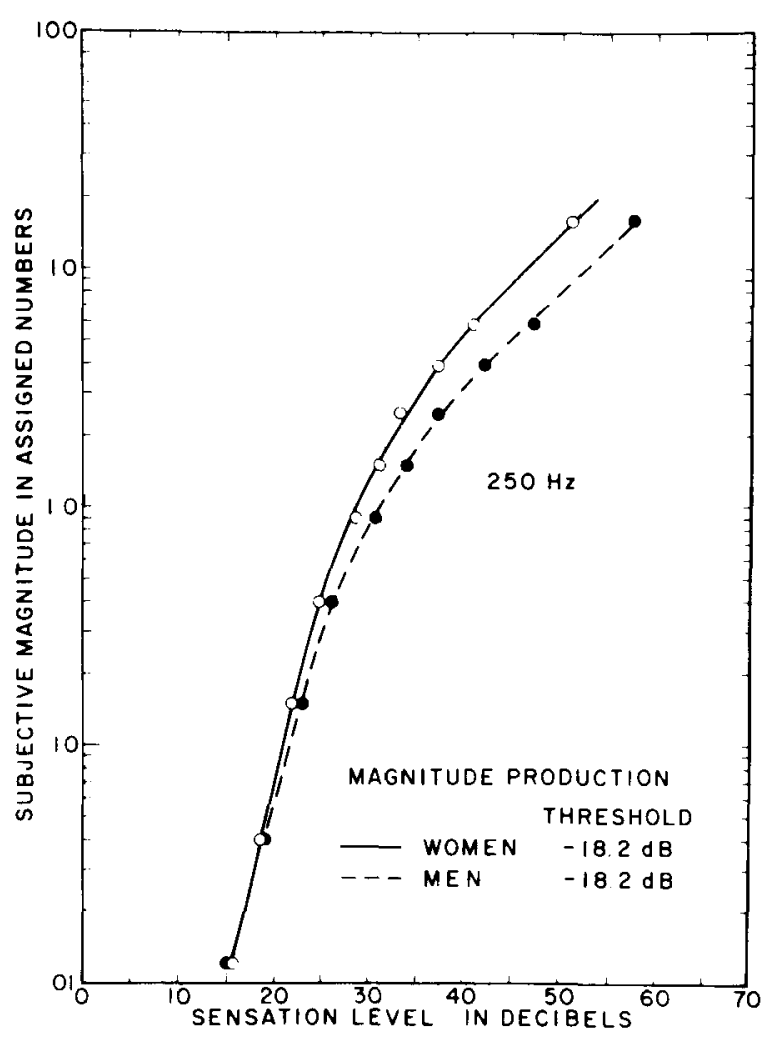

Figure 3. Magnitude production of vibrotactile sensation (geometric means) as a function of sensation level for men $(\bullet)$ and women (O). Vibration frequency was $250 \mathrm{~Hz}$.

sensitivity to vibration on the hand. This finding differs from that of Goff et al. (1965), who showed that women were generally more sensitive than men, but it is consistent with other reports that vibrotactile sensitivities for the two sexes were approximately equal (Plumb \& Meigs, 1961; Steinberg \& Graber, 1963; Verrillo \& Ecker, 1977). In a recent study (Verrillo, in press), the author measured vibration thresholds in five groups of subjects ranging in mean age from 10 to 65 years. The sex differences ranged from $.2 \mathrm{~dB}$ (age 65) to $4.4 \mathrm{~dB}$ (age 50) from decade to decade, but there was no consistent pattern to these differences. At some ages, women were more sensitive (age $10,3.8 \mathrm{~dB}$; age $35,4.3 \mathrm{~dB}$ ), at other ages men were more sensitive (age $50,4.4 \mathrm{~dB}$ ), and at still other age levels there were no differences (age 20, .34 dB; age $65, .30 \mathrm{~dB}$ ). This result does not lend itself to any firm generalizations about the existence of differences between sexes.

The configuration of the curve drawn through the data points in Figure 1 has been interpreted as indicative of at least two receptor systems for the mediation of vibrotactile sensations. The flat, low-frequency portion of the curve is thought to be the psychophysical result of activity in non-Pacinian cutaneous receptors and the U-shaped, high-frequency portion is the result of the activity of Pacinian corpuscles (Verrillo, 1963, 1966, 1968). This model of mechanoreception has been supported by a number of physiological studies (Lindblom, 1965; Talbot, DarianSmith, Kornhuber, \& Mountcastle, 1968; and others). Although there are anatomical studies showing systematic changes in the distribution and structure of cutaneous receptor end organs as a function of age (Cauna, 1965), the only sex-related difference reported was that Meissner corpuscles decreased in number with age more rapidly in males than in females. It is not likely that a loss of number in these receptors would be reflected in higher thresholds, since spatial summation is not a characteristic feature of the non-Pacinian receptors (Verrillo, 1968).

The scaling of sensory magnitudes, however, did show a difference between the sexes (Figures 2, 3, and 4). The results may be interpreted to mean that at suprathreshold levels of stimulation (above approximately $10 \mathrm{~dB} \mathrm{SL}$ ) women report the stimulus to be subjectively greater than do men. The growth of

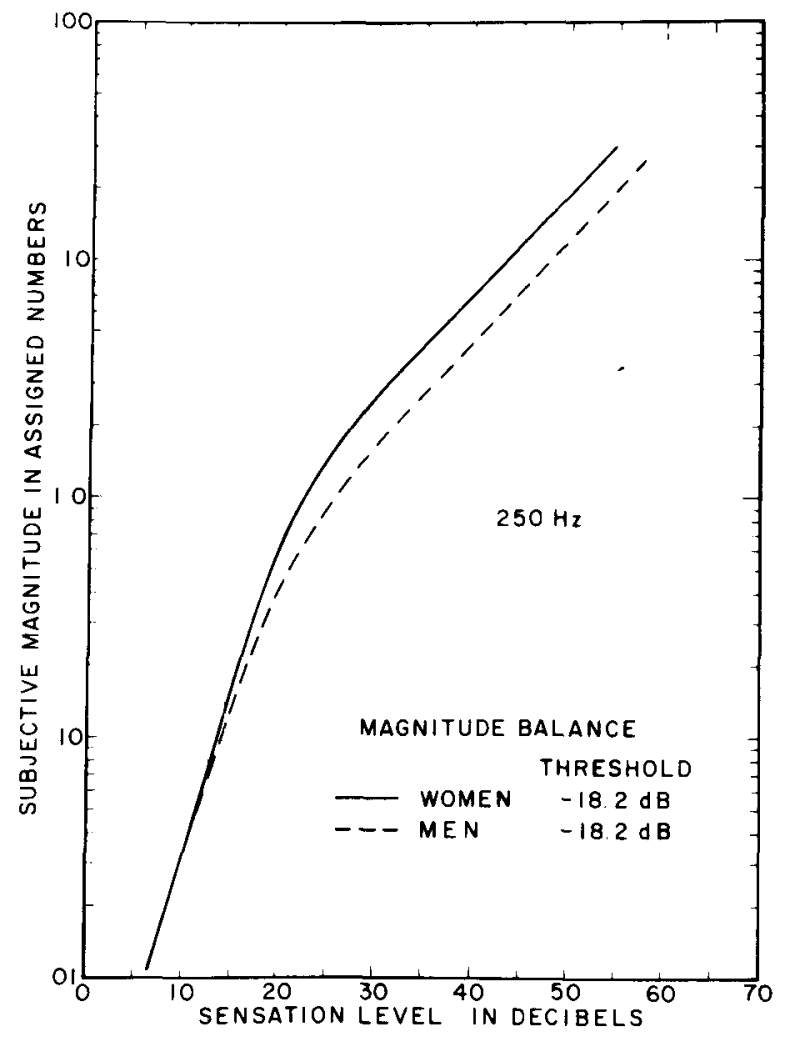

Figure 4. Numerical magnitude balance curves for women (solid line) and men (dashed line) calculated from the results shown in Figures 2 and 3 and plotted as a function of sensation level. Since the threshold at $250 \mathrm{~Hz}$ was the same $(-18.2 \mathrm{~dB})$ for both groups, both curves are presented on the same abscissa. The slope of both curves is approximately .45 above $25 \mathrm{~dB}$ SL. The higher position of the women's curve indicates that the same amplitude of vibration is subjectively greater for women than for men. 
subjective magnitude progresses at a faster rate for women at low intensity levels, but the growth rate is approximately equal for men and women at the higher levels of intensity. This suggests that the same vibrotactile sensation level delivered to the hands of men and women is perceived as more intense by the women. Since the thresholds of the groups did not differ, it may be stated also that the same absolute amplitude of vibration produces a sensation of greater magnitude in women than in men.

It may be argued that the results shown in Figures 2, 3 , and 4 mean, more simply, that the perceived magnitudes are the same for men and women, but that women are inclined to use larger numbers than men to represent the same sensory experience. This hypothesis may be tested by scaling the magnitude of another modality using the same procedure. If women tend simply to use larger numbers, this tendency should be detectable in another sense modality.

The hypothesis was tested by asking six men and six women to estimate the subjective lengths of seven lines projected upon a screen. The subjects were seated approximately $2.7 \mathrm{~m}$ from the screen in a room with fluorescent overhead lighting. The actual lengths of the lines on the screen were $1.4,2.8,5.0,13.2,26.6$, 53.5 , and $132.5 \mathrm{~cm}$. The subjects were instructed not to guess actual line length in conventional units of measurement, but to assign numbers whose subjective magnitudes matched the subjective magnitudes of the lines. No standard or modulus was used. The lines were presented in random order twice, with the restriction that the shortest and longest lines were never first in the sequence. The results of the two runs were averaged and the geometric means of the two groups are shown in Figure 5.

It is obvious that in the magnitude estimation of line length women do not have a tendency to use higher numbers than men. In this task, men and women gave very nearly the same numbers to match the subjective length of the lines. The resultant curve has a slope of .952 , close to the slope of 1.0 reported by Stevens (1961) and others.

A more stringent test of the hypothesis that women are not simply using larger numbers than men for the same amplitude of vibration would involve scaling both vibration and line length by magnitude estimation followed by a cross-modality match of the two sets of stimuli. Based on the results shown in Figure 5, however, it seems reasonable at this time to interpret the results of the vibrotactile experiments as indicating that the subjective magnitude of suprathreshold vibration is greater for women that it is for men.

The author was unable to find any studies in which sex comparisons were made for the perceived magnitude of sensation in other sense modalities. Corah and Boffa (1970), however, did show that women judged aversive white noise as more uncomfortable

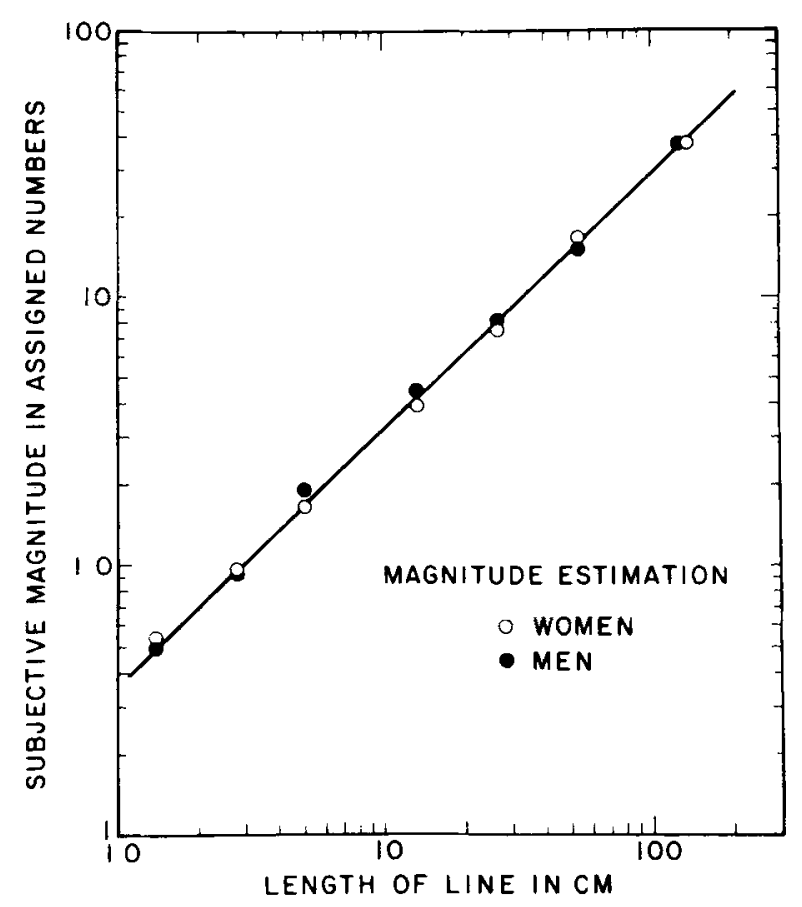

Figure 5. Absolute magnitude estimates (geometric means) of length of lines for a group of six men $(\bullet)$ and six women $(O)$ from a distance of $2.7 \mathrm{~m}$. The perceived length of lines is apparently the same for the two sexes, and there does not seem to be a tendency for women to use larger numbers than men.

than did men. Whether these judgments can be related to subjective intensity is open to question. The greater estimates of vibrotactile stimuli by women in the present study remain an unexplained phenomenon. It may relate to physiological differences in the neural mechanisms of men and women, but none thus far have been demonstrated for this system. It may, on the other hand, be linked to a heightened awareness of bodily sensations due to the focus placed on bodily functions by the onset of menses at puberty. This, coupled with the reinforcement provided by social conditioning, could account for the response to stimuli applied to the body. Why this should manifest itself only at suprathreshold levels is without explanation at this time. It should be interesting to compare auditory and visual subjective intensity functions in men and women. These stimuli are remote from the body, as were the estimated lines in this study, in contrast to vibrotactile stimuli which are applied directly to the body surface. If the suggestion offered above has validity, the auditory and visual functions of men and women should not differ.

\section{REFERENCES}

Cauna, N. The effects of aging on the receptor organs of the human dermis. In W. Montagna (Ed.), Advances in biology of skin (Vol. VI) Aging. New York: Pergamon, 1965.

Clark, W. C., \& MEHL, L. Thermal pain: A sensory decision 
theory analysis of the effect of age and sex on $d^{\prime}$, various response criteria, and $50 \%$ pain threshold. Journal of Abnormal Psychology, 1971, 78, 202-212.

Corah, N. L., \& Boffa, J. Perceived control, self-observation, and response to aversive stimulation. Journal of Personality \& Social Psychology, 1970, 16, 1-4.

Conso, J. F. Age and sex differences in pure-tone thresholds. Archives of Otolaryngology, 1963, 77, 385-405.

Gescheider, G. A. Evidence in support of the duplex theory of mechanoreception. Sensory Processes, 1976, 1, 68-76.

Goff, G. D., Rosner, B. S., Detre, T., \& Kennard, D. Vibration perception in normal man and medical patients. Journal of Neurology, Neurosurgery \& Psychiatry, 1965, 18, 503-509.

Hellman, R. P., \& Zwislocki, J. Monaural loudness function at $1,000 \mathrm{cps}$ and interaural summation. Journal of the Acoustical Society of America, 1963, 35, 856-865.

Koelega, H. S. Extraversion, sex, arousal and olfactory sensitivity. Acta Psychologica, 1970, 34, 51-66.

Köster, E. P. Olfactory sensitivity and the menstrual cycle. International Rhinology, 1965, 3, 57-64.

Le Magnen, J. L'olfaction: Le fonctionnement olfactif et son intervention dans les régulations psycho-physiologiques. Journal Physiologie Pathologie Général, 1953, 45, 285-326.

LindBlom, U. Properties of touch receptors in distal glabrous skin of the monkey. Journal of Neurophysiology, 1965, 28, 966-985.

Plumb, C. S., \& Meigs, J. W. Human vibration perception: Part I. Vibration perception at different ages. Archives of General Psychiatry, 1961, 4, 611-614.

Procacci, P., Zoppi, M., Maresca, M., \& Romano, S. Studies on the pain threshold in man. In J. J. Bonica (Ed.), Advances in neurology (Vol. 4). International symposium on pain. New York: Raven, 1974.

Schne IDER, R. A. The sense of smell in man. New England Journal of Medicine, 1967, 277, 299-303.
Spoor, A. Presbyacusis values in relation to noise induced hearing loss. International Audiology, 1967, 6, 48-57.

Steinberg, F. U., \& Graber, A. L. The effect of age and peripheral circulation on the perception of vibration. Archives of Physical Medicine and Rehabilitation, 1963, 44, 645-650.

Stevens, S. S. The psychophysics of sensory function. In W. A. Rosenblith (Ed.), Sensory communication. Cambridge, Mass: MIT Press, 1961.

Talbot, W. H., Darian-Smith, I., Kornhuber, H. H., \& Mountcastle, V. B. The sense of flutter-vibration: Comparison of the human capacity with response patterns of mechanoreceptive afferents in the monkey hand. Journal of Neurophysiology, 1968, 31, 301-334.

VERRILLO, R. T. Effect of contactor area on the vibrotactile threshold. Journal of the Acoustical Society of America, 1963, 35, 1962-1966.

Verrillo, R. T. Specificity of a cutaneous receptor. Perception \& Psychophysics, 1966, 1, 149-153.

VERRILLO, R. T. A duplex mechanism of mechanoreception. In D. R. Kenshalo (Ed.), The skin senses. Springfield, Ill: Thomas, 1968.

VERRILLO, R. T. Change in vibrotactile thresholds as a function of age. Sensory Processes, in press.

Verrillo, R. T., \& Ecker, A. D. Effects of root or nerve destruction on vibrotactile sensitivity in trigeminal neuralgia. Pain, 1977, 3, 239-255.

Verrillo, R. T., Fraioli, A. J., \& Smith, R. L. Sensation magnitude of vibrotactile stimuli. Perception \& Psychophysics, $1969,6,366-372$.

(Received for publication February 12, 1979; revision accepted May 23, 1979.) 